\title{
The Identification of the Sex Chromosome and Karyotype of Four Toad Species (Genus Bufo) in Thailand by T-lymphocyte Cell Culture
}

\author{
Pornnarong Siripiyasing ${ }^{1}$, Warawut Chulalaksananukul ${ }^{2}$, \\ Putsatee Pariyanonth ${ }^{3}$, Sarawut Kaewsri ${ }^{4}$, Sarawut Sittigul ${ }^{5}$, \\ Namphunk Seatung ${ }^{6}$ and Alongkoad Tanomtong ${ }^{6, *}$

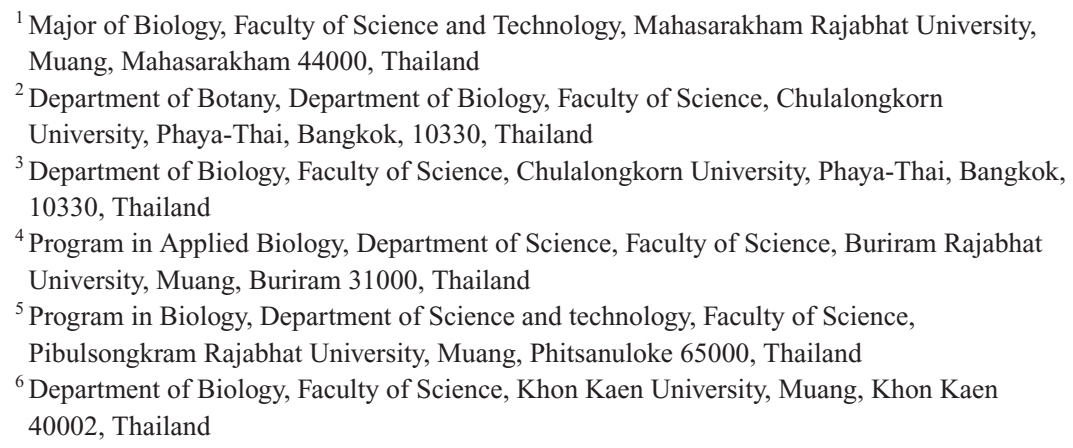

Received May 24, 2008; accepted July 12, 2008

\begin{abstract}
Summary Our knowledge is the first report on karyotypic study of four toad species (genus Bufo) in Thailand namely; large-eared toad (Bufo macrotis Boulenger 1887), Indochinese dwarf toad (Bufo parvus Boulenger 1887), common Indian toad (Bufo melanostictus Schneider 1799) and river giant toad (Bufo asper Gravenhorst 1829). Blood samples were taken from 5 males and 5 females of each four toad species. After the standard whole blood T-lymphocyte culture in the presence of colchicine, the metaphase spreads were performed on microscopic slides and air-dried. Conventional staining, G-banding and C-banding techniques were applied to stain the chromosomes. The results indicated $2 n=22$ and fundamental number (NF) 44 in both male and female of four toad species. The autosomes of $B$. macrotis and B. melanostictus is being as 18 metacentric and 4 submetacentric chromosomes while $B$. parvus and $B$. asper is as 16 metacentric and 6 submetacentric chromosomes. Gbanding technique showed a $B$. melanostictus's constriction on short arm of Y chromosome (the largest chromosome) but did not show on $\mathrm{X}$ chromosome. C-banding technique demonstrated a dark band constriction on $\mathrm{Y}$ chromosome of B. melanostictus, the representative of constitutive heterochromatin. However, there is no dark band constriction on $\mathrm{X}$ chromosome. So, we conclude that the sex determination of $B$. melanostictus is $\mathrm{XY}$ system. Although we do not treat $B$. macrotis, $B$. parvus and $B$. asper with G-banding and C-banding technique, we also predict that those three species have the same sex determination as $B$. melanostictus. We extremely appreciate to public our present research, the first cytogenetic study of B. macrotis and B. asper.
\end{abstract}

Key words Chromosome, Large-eared toad (Bufo macrotis), River giant toad (Bufo asper), Indochinese dwarf toad (Bufo parvus), Common Indian toad (Bufo melanostictus)

General amphibians are belonging to the phylum Chordata, class Amphibia, subclass Lissamphibia and three orders as following: order Gymonphina (Apoda), Caudata (Urodela) and Anura (Salientia) (Duellman 1982). Amphibians in the family Bufonidae (toad) in Thailand have 4 genera including Ansonia, Leptophryne, Pedostibes and Bufo. There are 4 species in genus Bufo. In this re-

*Corresponding author, e-mail: tanomtong@hotmail.com 


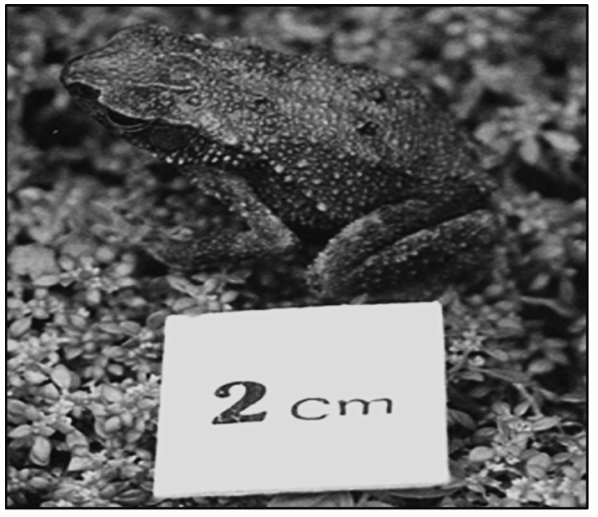

A.

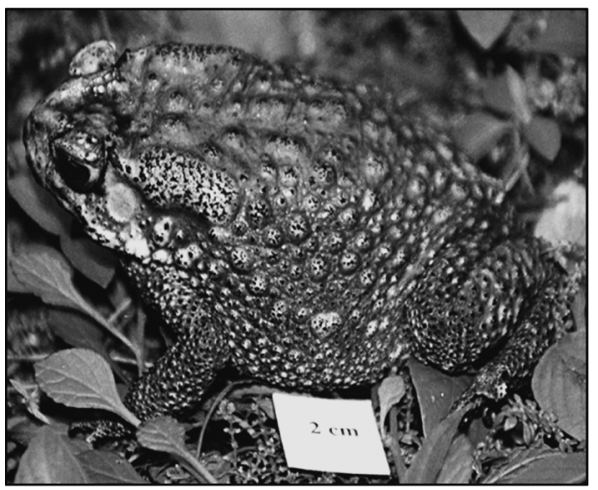

C.

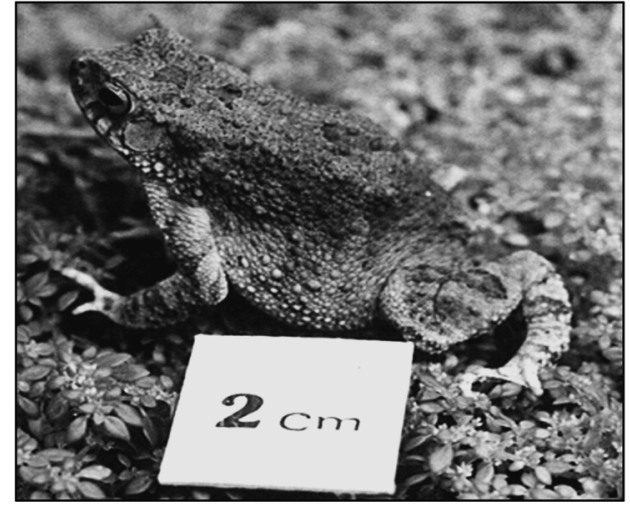

B.

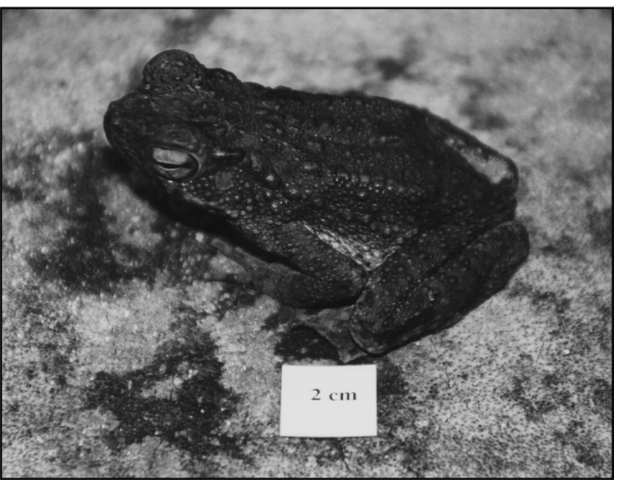

D.

Fig. 1. Four toad species of the genus Bufo in Thailand namely; large-eared toad, Bufo macrotis (A) Indochinese dwarf toad, Bufo parvus (B) common Indian toad, Bufo melanostictus (C) and river giant toad, Bufo asper (D). Photograph: Pornnarong Siripiyasing and Alongkoad Tanomtong.

search, we have studied all species of the genus Bufo including large-eared toad (Bufo macrotis Boulenger 1887), Indochinese dwarf toad (Bufo parvus Boulenger 1887), common Indian toad (Bufo melanostictus Schneider 1799) and river giant toad (Bufo asper Gravenhorst 1829) (Fig. 1). The feature characteristic of genus $B u f o$ are an oval and untwines elongate tongue, no vomerine tooth, no web on toes, one vocal sac, horizontal oval pupil and obviously parotid gland (Taylor 1962).

In early nineteenth century knowledge, several scientists accepted that amphibians have no sex-chromosome (Solari 1994). In later stage, banding technique was established for chromosome staining which can identify type of sex-chromosome. Amphibians sex-chromosome staining indicated that some species have similar chromosome type but have difference banding pattern. It revealed that there are some genes involved in sex-determination on the chromosome (Schmid et al. 1991). All previous knowledge demonstrated that there are several patterns of sex-chromosomes; a group which have difference type and size of sex-chromosome (Schmid 1980, Schmid et al. 1983, 1988, Kuramoto 1980, Mahony 1991, Nishioka et al. 1994), a group which have difference banding pattern of sex-chromosome (Iturra and Veloso 1989, Schmid et al. 1989, 1990, 1991, 1993), a group which have supernumerary of sex-chromosome (Schmid 1978a, Green 1998) and a group which have complex pattern or have no difference type and size of sex-chromosome (Schmid et al. 

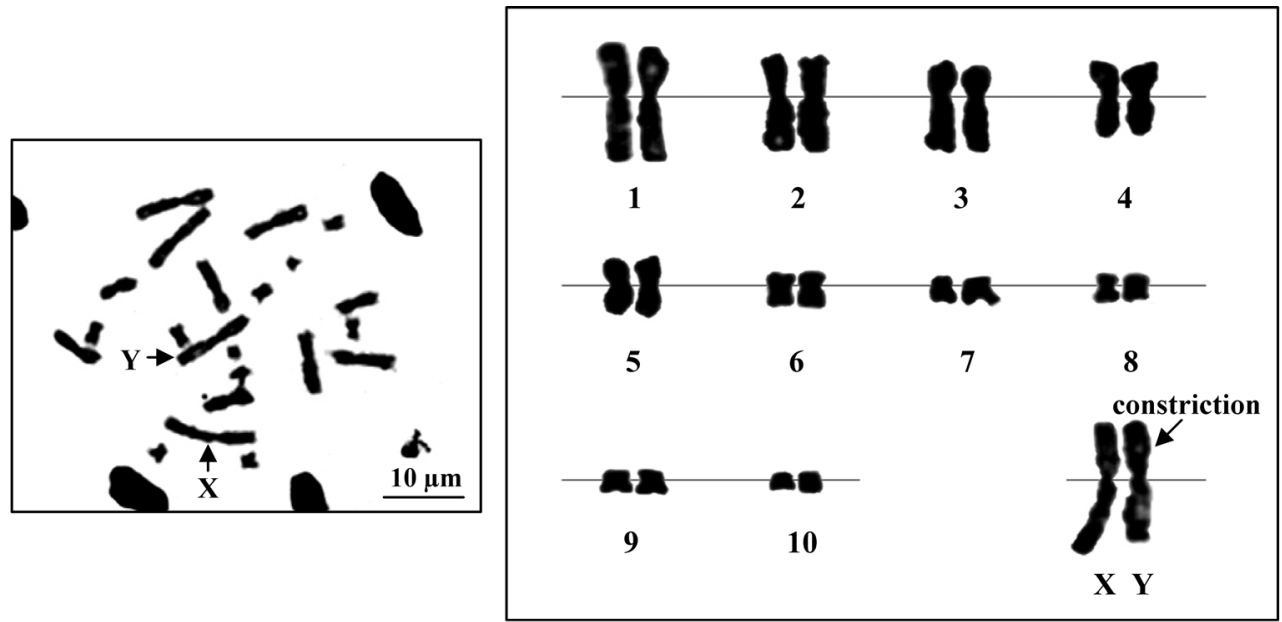

A. The male common Indian toad (Bufo melanostictus)
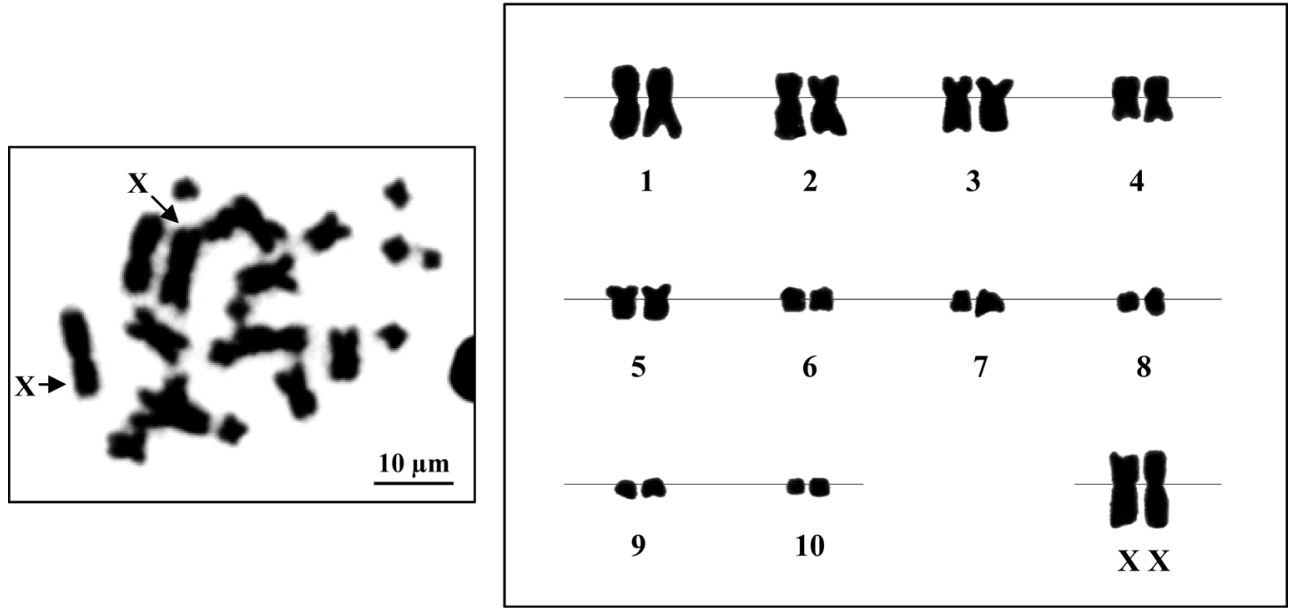

B. The female common Indian toad (Bufo melanostictus)

Fig. 2. Metaphase chromosome plates and karyotypes of male (A) and female (B) common Indian toad (Bufo melanostictus Schneider 1799) $2 n$ (diploid)=22 by conventional staining technique, showing sex chromosomes (arrows).

1978b, 1992, Kuramoto 1980, Schempp and Schmid 1981, Nishioka et al. 1987, Melo et al. 1995, Ota and Matsui 1995).

There are numerous cytogenetic reports on toads in genus Bufo (Bogart 1966, Beckert and Doyle 1967, Cole et al. 1968, Schmid 1978a, 1978b, Narkkasem 1975, Supaporm and Kanlayaprasith 1990). However, there is no report on B. macrotis and B. asper. This is the first cytogenetic study on those two species as described above.

Materials and methods

Blood samples of 5 males and 5 females of each four toad species in Thailand were collected 

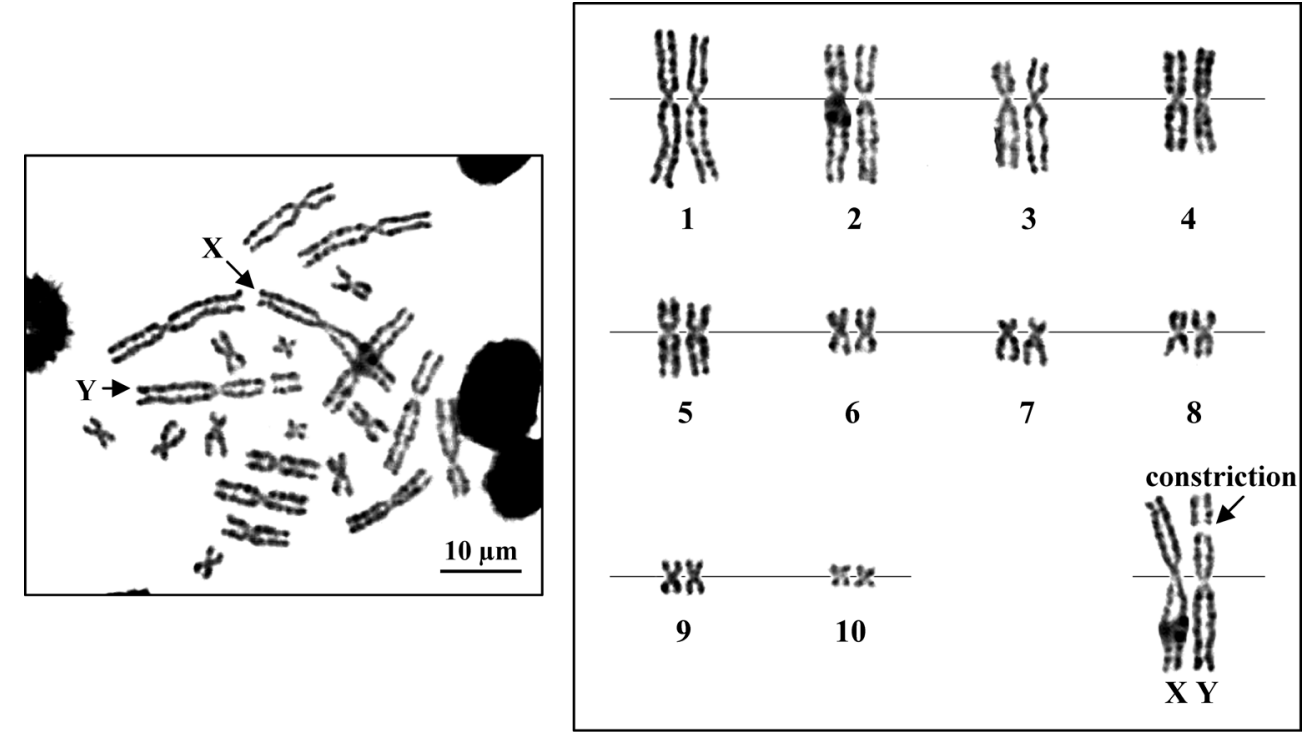

A. The male common Indian toad (Bufo melanostictus)

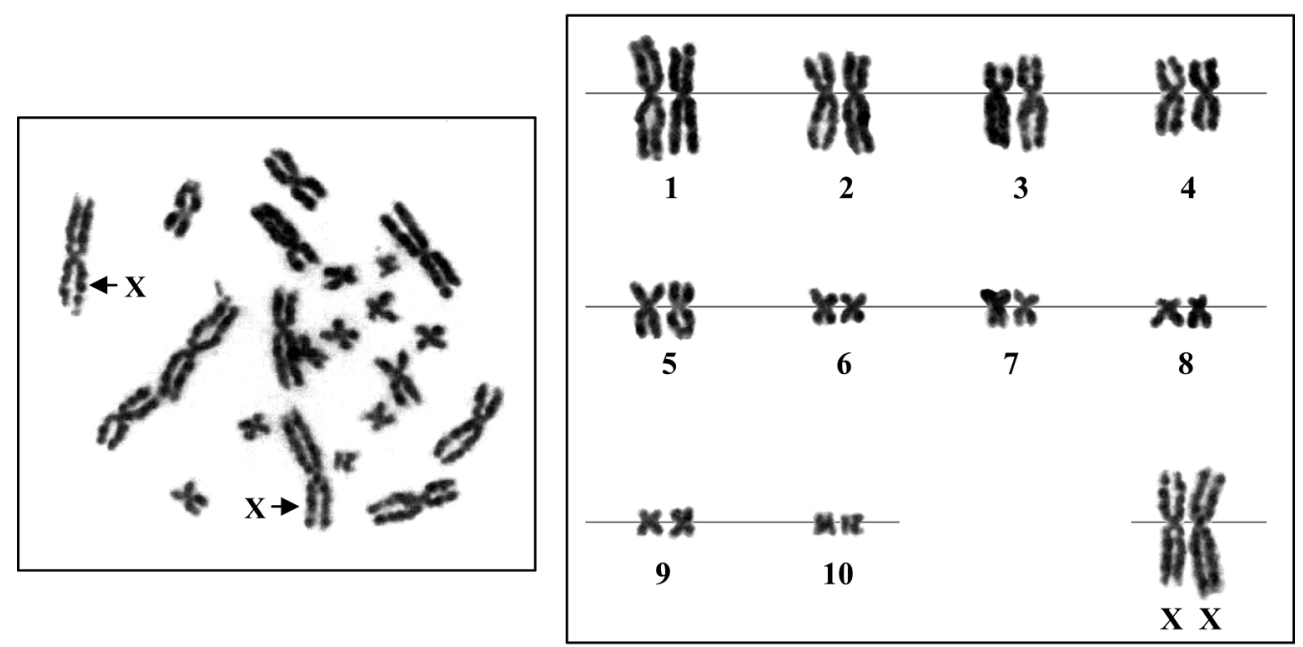

B. The female common Indian toad (Bufo melanostictus)

Fig. 3. Metaphase chromosome plates and karyotypes of male (A) and female (B) common Indian toad (Bufo melanostictus Schneider 1799) $2 n$ (diploid)=22 by G-banding technique, showing sex-chromosomes (arrows).

from Songkla and Kanchanaburi Provinces and then applied for cytogenetic studies by lymphocyte culture of whole blood samples. The culture cells were treated with a colchicine-hypotonic-fixationair-drying technique followed by conventional staining, G-banding and C-banding techniques with Giemsa's (Rooney 2001, Campiranon 2003). Twenty cells of each individual chromosome checks accomplished by using a light microscope (Chaiyasut 1989). 

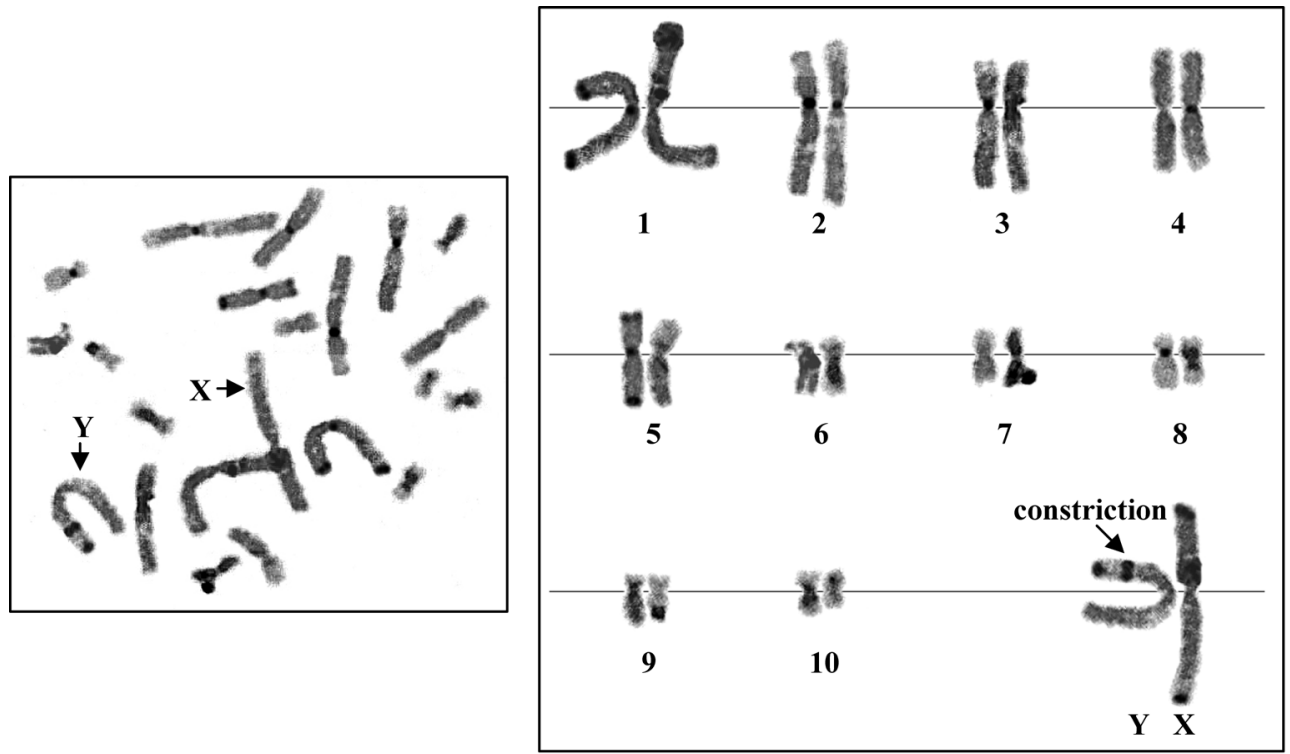

A. The male common Indian toad (Bufo melanostictus)
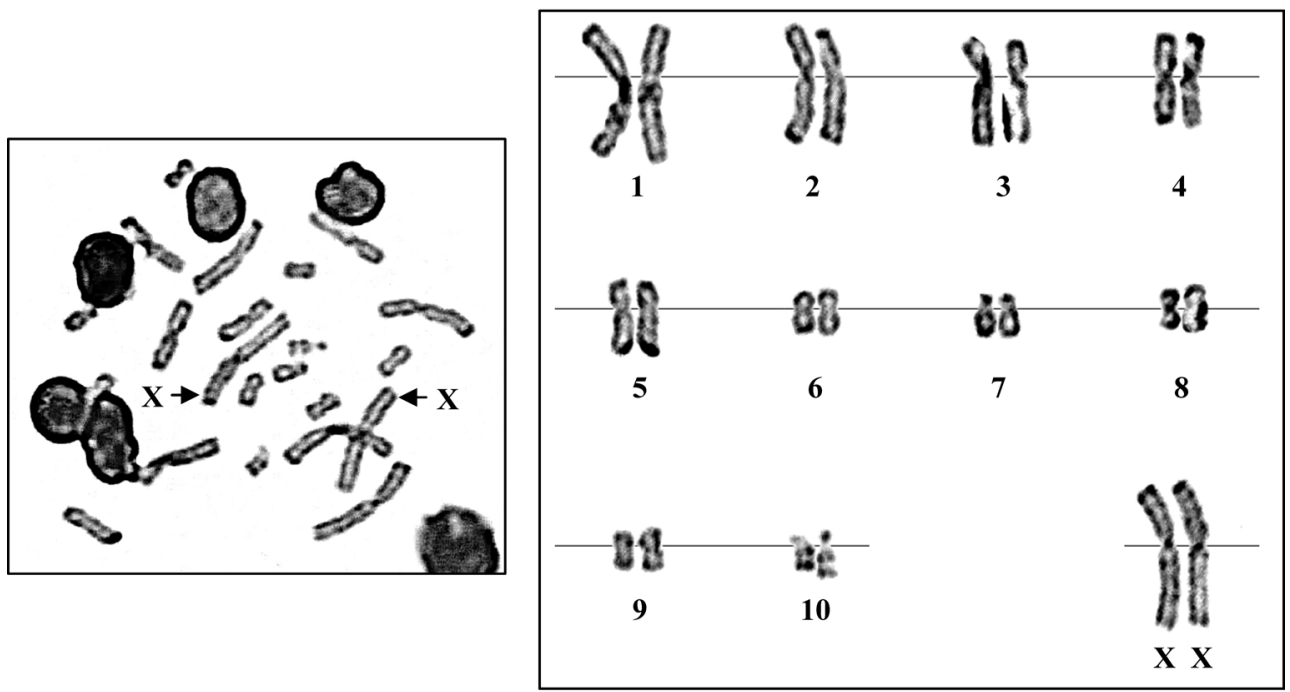

B. The female common Indian toad (Bufo melanostictus)

Fig. 4. Metaphase chromosome plates and karyotypes of male (A) and female (B) common Indian toad (Bufo melanostictus Schneider 1799) $2 n$ (diploid)=22 by C-banding technique, showing sex-chromosomes (arrows).

\section{Results and discussion}

We found that all of four toad species in Thailand: B. macrotis, B. parvus, B. melanostictus and B. asper's chromosome numbers are $2 n=22$ (Fig. 8). The result is consistent to the report of Bogat (1966), Beckert and Doyle (1967), Cole et al. (1968), Schmid (1978a), Supaporm and Kanlayaprasith (1990), Narkkasem (1975), which revealed that most species of genus Bufo have $2 n=22$ except 

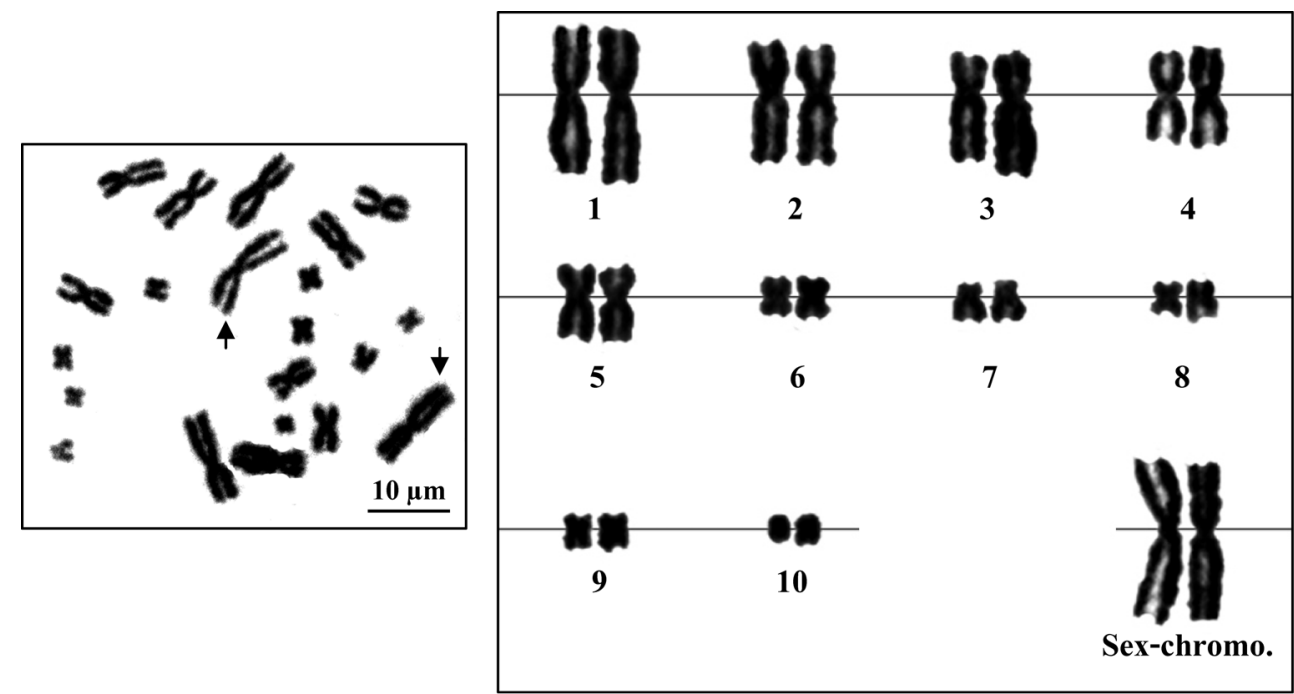

A. The male large-eared toad (Bufo macrotis)

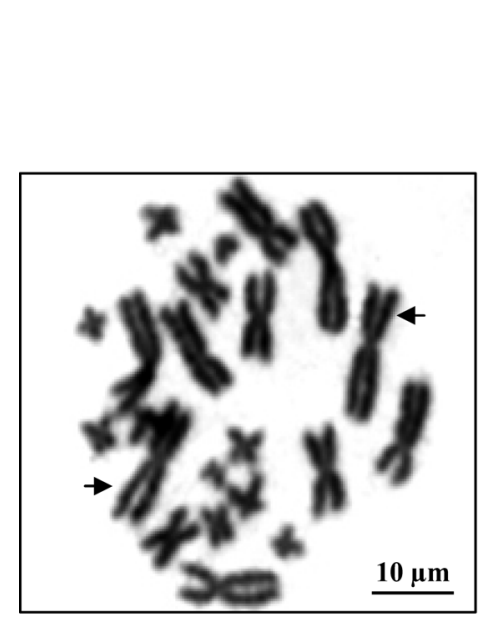

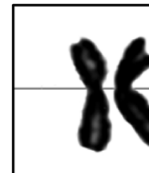

1

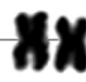

5

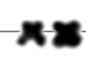

9

10

2

6
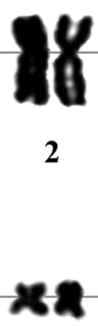

3

4

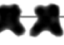

8

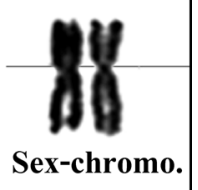

B. The female large-eared toad (Bufo macrotis)

Fig. 5. Metaphase chromosome plates and karyotypes of male (A) and female (B) large-eared toad (Bufo macrotis Boulenger 1887) $2 n$ (diploid) $=22$ by conventional staining technique, showing sex-chromosomes (arrows).

in 6 species which are existence in Africa: B. regularis, B. gutturalis, B. garmani, B. rangeri, B. brauni and $B$. latifrons that have $2 n=20$. Several scientist guest that Africa is the original native of genus $B u f o(2 n=20)$. After that, they have change in chromosome number $(2 n=22)$ and then have been distributing throughout the world (Bogart 1966).

We also found that both of male and female of all of four toad species in Thailand: $B$. macrotis, B. parvus, B. melanostictus and B. asper's fundamental number (NF) are 44. The autosome types of $B$. macrotis and B. melanostictus were being as 18 metacentric and 4 submetacentric 

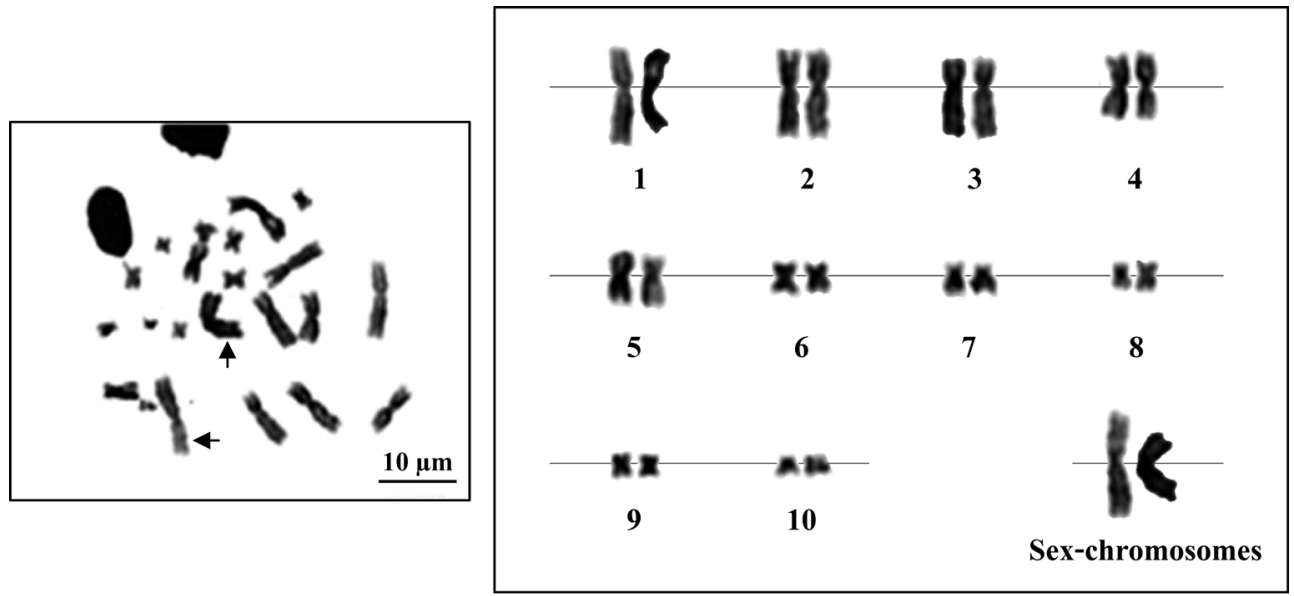

A. The male Indochinese dwarf toad (Bufo parvus)

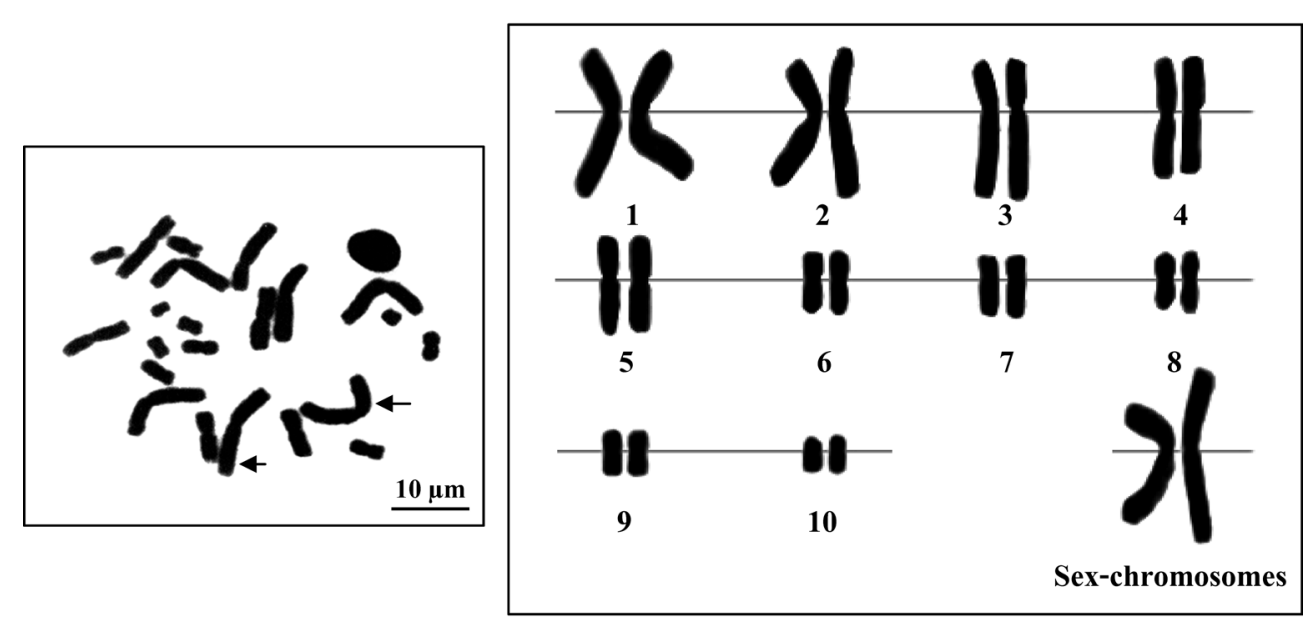

B. The female Indochinese dwarf toad (Bufo parvus)

Fig. 6. Metaphase chromosome plates and karyotypes of male (A) and female (B) Indochinese dwarf toad (Bufo parvus Boulenger 1887) $2 n$ (diploid) $=22$ by conventional staining technique, showing sexchromosomes (arrows).

chromosomes (Figs. 2-5) while B. parvus and B. asper were as 16 metacentric and 6 submetacentric chromosomes (Figs. 6, 7). It is not much differ from the reports of Narkkasem (1975) and Supaporm and Kanlayaprasith (1990) that revealed the 18 metacentric and 4 submetacentric chromosomes of B. melanostictus's autosome types. Moreover, it is quite consistent to Cole et al. (1968) that report the submetacentric and metacentric chromosomes of eight species of genus Bufo which are existence in North America.

The autosome size of B. macrotis, B. parvus and B. melanostictus are being as 5 large chromosome pairs, 1 medium pair and 5 small pairs (Tables $1-3$ ) while $B$. asper is as 5 large chromosome pairs and 6 small pairs (Table 4). Our result have much consistent to Narkkasem (1975) and Supaporm and Kanlayaprasith (1990) that revealed the 5 large chromosome pairs, 1 medium pair and 5 


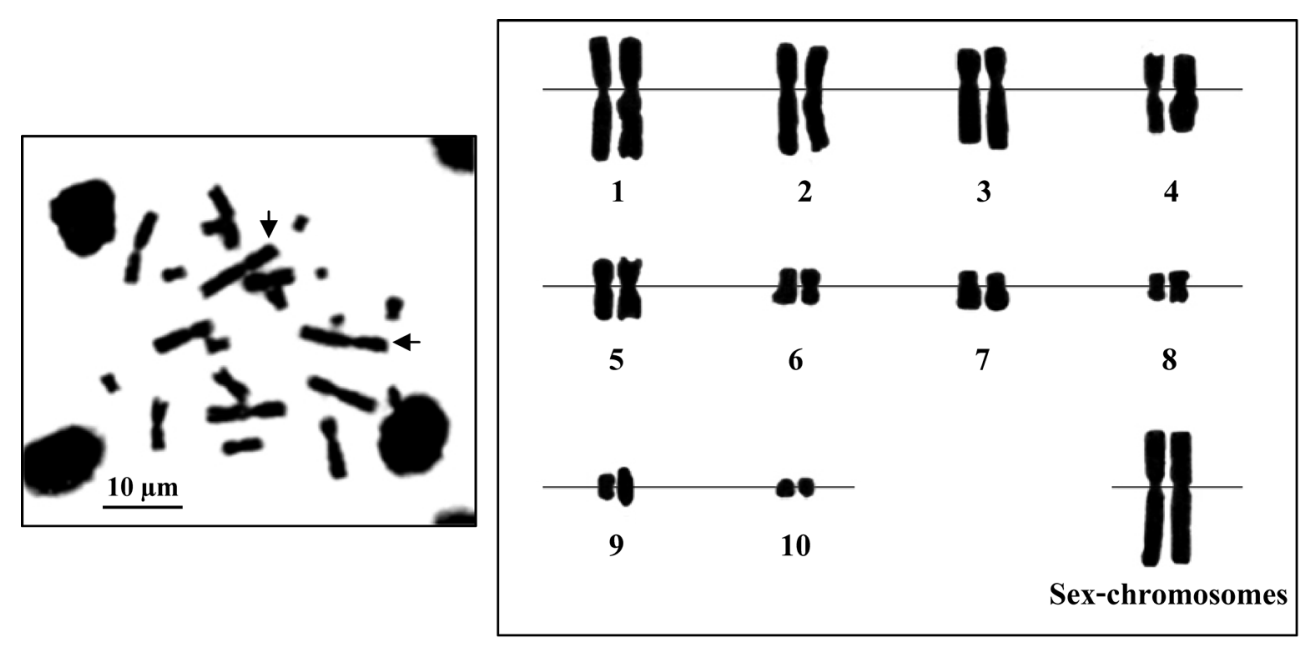

A. The male river giant toad (Bufo asper)

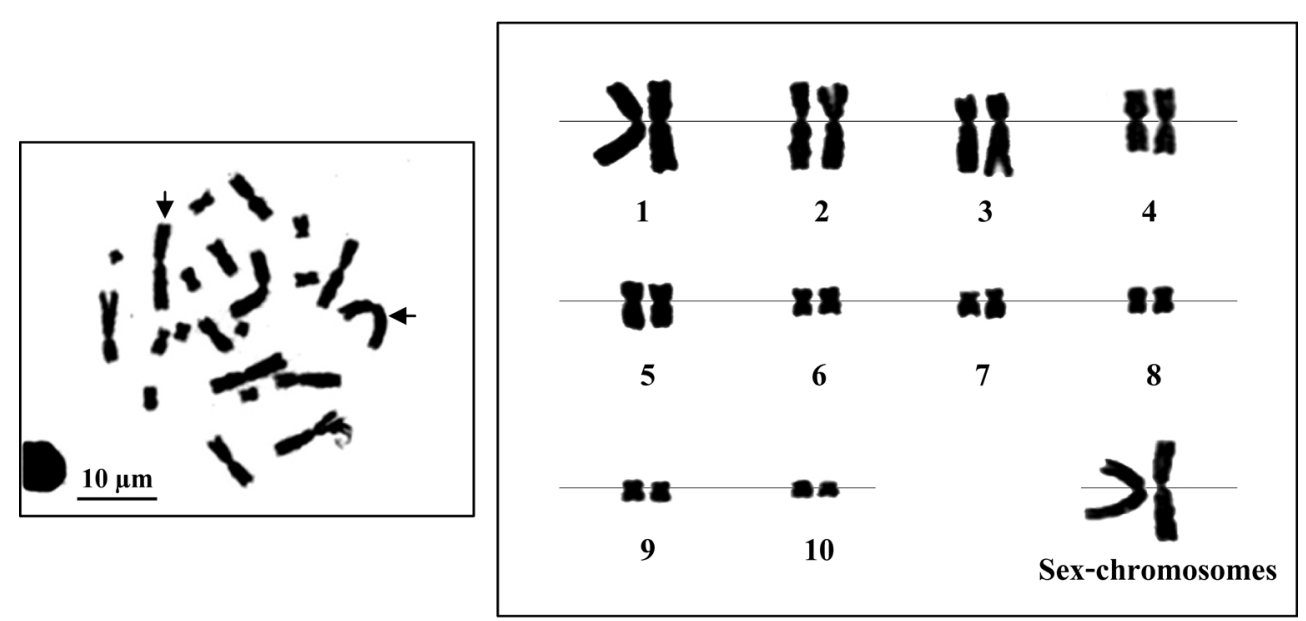

B. The female river giant toad (Bufo asper)

Fig. 7. Metaphase chromosome plates and karyotypes of male (A) and female (B) river giant toad (Bufo asper Gravenhorst 1829) $2 n$ (diploid)=22 by conventional staining technique, showing sex-chromosomes (arrows).

small pairs of $B$. melanostictus's autosome sizes. At this point of our knowledge, the cytogenetic study of B. macrotis and B. parvus, this is the first report.

G-banding technique showed the B. melanostictus's constriction on short arm of Y chromosome (the largest chromosome) but not show on $\mathrm{X}$ chromosome. Those feature is appeared in all male metaphase plate cells. So that, we agree that the sex determination of B. melanostictus is XY system (Figs. 3, 9). It is much similar to the reports of Iturra and Veloso (1989), Schmid et al. $(1989,1990,1991,1993)$ which demonstrated that several amphibian species has the same chromosome type and size but has a different band patterns by banding techniques. G-banding technique can show the labels of histone protein stained (only histone protein which exist on nitrogenous base AT-rich DNA regions) by Giemsa's dye (Summer 1990). 

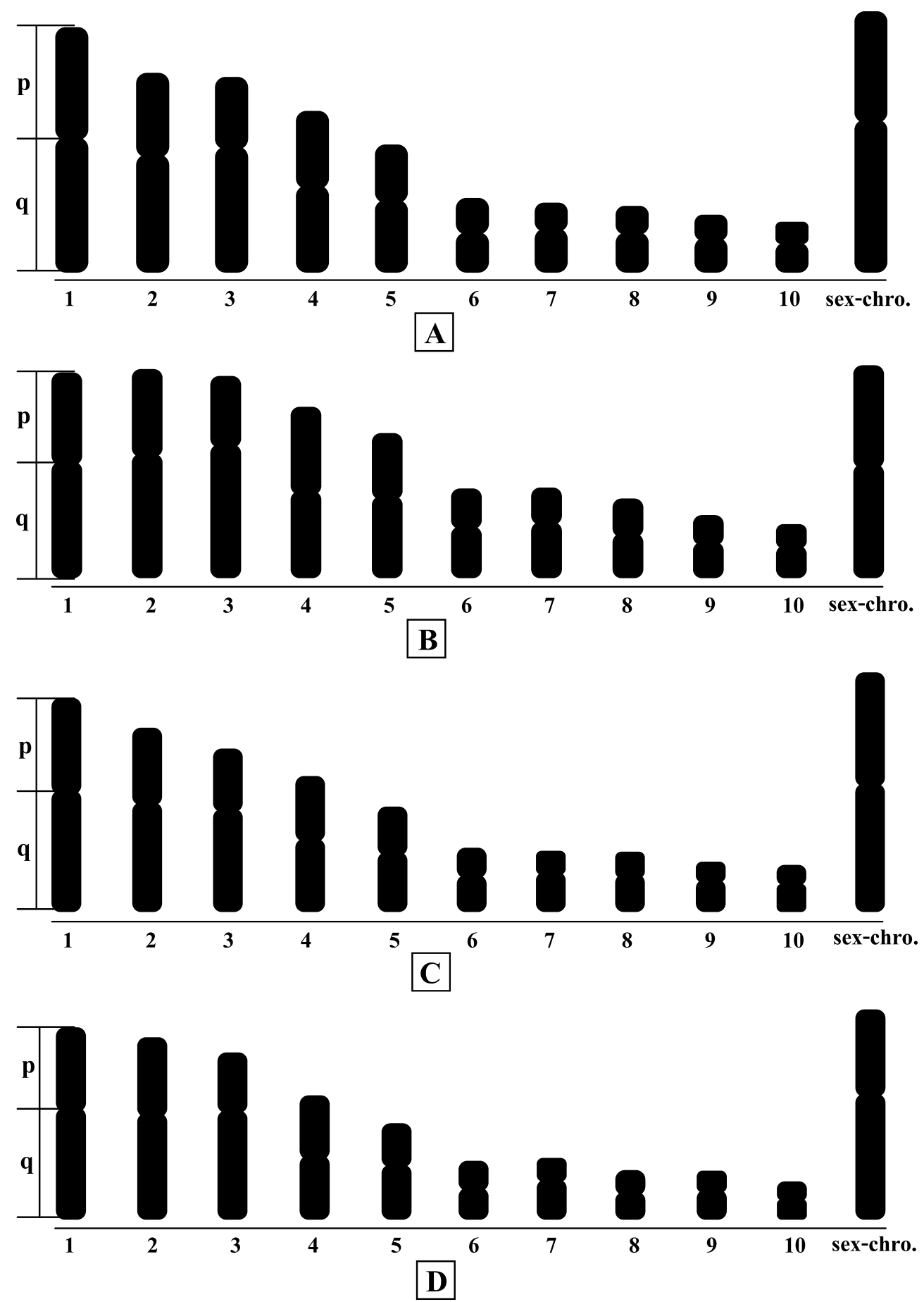

Fig. 8. Idiogram of four toad species of the genus Bufo in Thailand namely; large-eared toad, Bufo macrotis (A) Indochinese dwarf toad, Bufo parvus (B) common Indian toad, Bufo melanostictus (C) and river giant toad, Bufo asper (D). * sex-chro.=sex-chromosomes. 


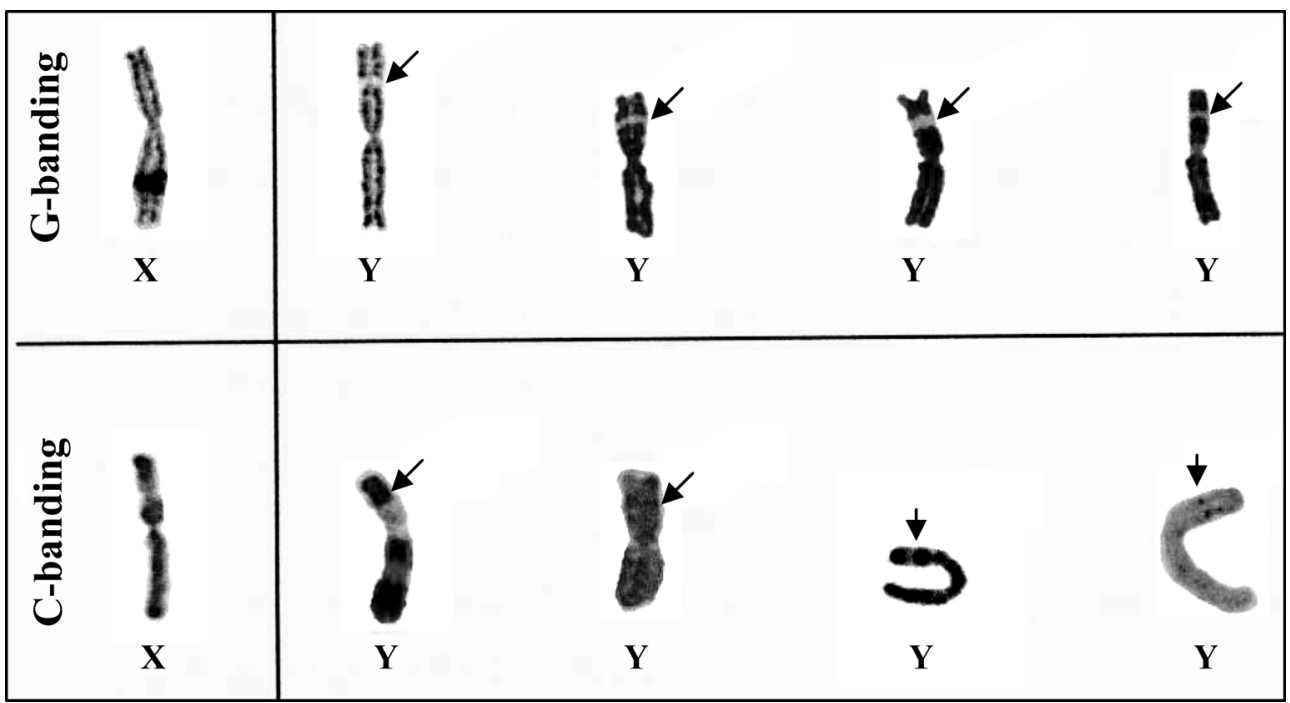

Fig. 9. Sex-chromosomes of common Indian toad (Bufo melanostictus Schneider 1799) indicated the presence of heteromorphism of $\mathrm{X}$ and $\mathrm{Y}$ chromosomes in male, there is a constriction and dark band (arrows) on Y chromosome by G-banding and C-banding techniques, respectively but not show on $\mathrm{X}$ chromosome.

Table 1. Mean of length short arm chromosome (Ls), length long arm chromosome (LL), length total arm chromosome (LT), relative length (RL), centromeric index (CI) and standard deviation (SD) of RL, CI from metaphase chromosomes of 20 cells in male and female common Indian toad (Bufo melanostictus) $2 n$ (diploid) $=22$

\begin{tabular}{|c|c|c|c|c|c|c|c|}
\hline $\begin{array}{l}\text { Chromosome } \\
\text { pairs }\end{array}$ & $\mathrm{Ls}$ & LL & LT & $\mathrm{RL}+\mathrm{SD}$ & $\mathrm{CI}+\mathrm{SD}$ & $\begin{array}{l}\text { Chromosome } \\
\text { size }\end{array}$ & $\begin{array}{c}\text { Chromosome } \\
\text { type }\end{array}$ \\
\hline 1 & 0.69 & 0.89 & 1.56 & $0.088 \pm 0.012$ & $0.557 \pm 0.052$ & large & metacentric \\
\hline 2 & 0.59 & 0.87 & 1.35 & $0.076 \pm 0.008$ & $0.562 \pm 0.011$ & large & metacentric \\
\hline 3 & 0.45 & 0.76 & 1.20 & $0.067 \pm 0.005$ & $0.625 \pm 0.176$ & large & submetacentric \\
\hline 4 & 0.51 & 0.75 & 1.05 & $0.059 \pm 0.003$ & $0.514 \pm 0.182$ & large & metacentric \\
\hline 5 & 0.37 & 0.54 & 0.82 & $0.046 \pm 0.001$ & $0.548 \pm 0.049$ & medium & metacentric \\
\hline 6 & 0.25 & 0.27 & 0.52 & $0.029 \pm 0.006$ & $0.519 \pm 0.172$ & small & metacentric \\
\hline 7 & 0.09 & 0.39 & 0.48 & $0.027 \pm 0.007$ & $0.812 \pm 0.156$ & small & metacentric \\
\hline 8 & 0.23 & 0.23 & 0.46 & $0.026 \pm 0.007$ & $0.500 \pm 0.163$ & small & metacentric \\
\hline 9 & 0.18 & 0.23 & 0.41 & $0.023 \pm 0.008$ & $0.560 \pm 0.020$ & small & metacentric \\
\hline 10 & 0.11 & 0.20 & 0.31 & $0.017 \pm 0.010$ & $0.645 \pm 0.020$ & small & submetacentric \\
\hline Sex-chromo. & 0.76 & 0.89 & 1.65 & $0.093 \pm 0.014$ & $0.539 \pm 0.106$ & large & metacentric \\
\hline
\end{tabular}

C-banding technique demonstrated a dark band constriction on Y chromosome of B. melanostictus, the representative of constitutive heterochromatin. However, there is no dark band constriction on X chromosome (Figs. 4, 9). The dark bands those appear by C-banding technique are obviously arises on centromeres, telomeres and some parts of its regions.

G-banding and C-banding techniques led us to conclude that the largest chromosome pair of male B. melanostictus is polymorphism (heteromorphism $\mathrm{X}$ and $\mathrm{Y}$ chromosome). The conclusion is consistent to Mahony (1991) that demonstrated sex-chromosome of Crinia bilingual using C-banding and NOR-banding techniques. According to his study, he concluded that the sex determination of those species is ZW system. His C-banding results showed a dark band on constitutive hete- 
Table 2. Mean of length short arm chromosome (Ls), length long arm chromosome (LL), length total arm chromosome (LT), relative length (RL), centromeric index (CI) and standard deviation (SD) of RL, CI from metaphase chromosomes of 20 cells in male and female large-eared toad (Bufo macrotis) $2 n$ (diploid) $=22$

\begin{tabular}{|c|c|c|c|c|c|c|c|}
\hline $\begin{array}{l}\text { Chromosome } \\
\text { pairs }\end{array}$ & Ls & LL & LT & $\mathrm{RL}+\mathrm{SD}$ & $\mathrm{CI}+\mathrm{SD}$ & $\begin{array}{c}\text { Chromosome } \\
\text { size }\end{array}$ & $\begin{array}{c}\text { Chromosome } \\
\text { type }\end{array}$ \\
\hline 1 & 0.70 & 0.80 & 1.50 & $0.084 \pm 0.010$ & $0.533 \pm 0.090$ & large & metacentric \\
\hline 2 & 0.56 & 0.77 & 1.33 & $0.074 \pm 0.007$ & $0.578 \pm 0.065$ & large & metacentric \\
\hline 3 & 0.47 & 0.75 & 1.22 & $0.068 \pm 0.005$ & $0.614 \pm 0.198$ & large & submetacentric \\
\hline 4 & 0.52 & 0.55 & 1.07 & $0.060 \pm 0.003$ & $0.514 \pm 0.147$ & large & metacentric \\
\hline 5 & 0.39 & 0.47 & 0.86 & $0.048 \pm 0.006$ & $0.546 \pm 0.096$ & medium & metacentric \\
\hline 6 & 0.25 & 0.27 & 0.52 & $0.029 \pm 0.006$ & $0.519 \pm 0.156$ & small & metacentric \\
\hline 7 & 0.18 & 0.32 & 0.50 & $0.028 \pm 0.006$ & $0.640 \pm 0.129$ & small & submetacentric \\
\hline 8 & 0.20 & 0.24 & 0.44 & $0.024 \pm 0.008$ & $0.545 \pm 0.084$ & small & metacentric \\
\hline 9 & 0.16 & 0.22 & 0.38 & $0.021 \pm 0.009$ & $0.578 \pm 0.030$ & small & metacentric \\
\hline 10 & 0.13 & 0.18 & 0.31 & $0.017 \pm 0.010$ & $0.580 \pm 0.150$ & small & metacentric \\
\hline Sex-chromo. & 0.79 & 0.91 & 1.70 & $0.095 \pm 0.010$ & $0.530 \pm 0.071$ & large & metacentric \\
\hline
\end{tabular}

Table 3. Mean of length short arm chromosome (Ls), length long arm chromosome (LL), length total arm chromosome (LT), relative length (RL), centromeric index (CI) and standard deviation (SD) of $\mathrm{RL}, \mathrm{CI}$ from metaphase chromosomes of 20 cells in male and female Indochinese dwarf toad (Bufo parvus) $2 n$ (diploid) $=22$

\begin{tabular}{|c|c|c|c|c|c|c|c|}
\hline $\begin{array}{c}\text { Chromosome } \\
\text { pairs }\end{array}$ & Ls & LL & LT & $\mathrm{RL}+\mathrm{SD}$ & $\mathrm{CI}+\mathrm{SD}$ & $\begin{array}{l}\text { Chromosome } \\
\text { size }\end{array}$ & $\begin{array}{c}\text { Chromosome } \\
\text { type }\end{array}$ \\
\hline 1 & 0.72 & 0.92 & 1.64 & $0.087 \pm 0.012$ & $0.560 \pm 0.055$ & large & metacentric \\
\hline 2 & 0.62 & 0.83 & 1.45 & $0.077 \pm 0.008$ & $0.572 \pm 0.008$ & large & metacentric \\
\hline 3 & 0.49 & 0.85 & 1.34 & $0.071 \pm 0.006$ & $0.634 \pm 0.005$ & large & submetacentric \\
\hline 4 & 0.57 & 0.60 & 1.17 & $0.062 \pm 0.003$ & $0.512 \pm 0.116$ & large & metacentric \\
\hline 5 & 0.40 & 0.49 & 0.89 & $0.047 \pm 0.009$ & $0.550 \pm 0.176$ & medium & metacentric \\
\hline 6 & 0.26 & 0.30 & 0.56 & $0.030 \pm 0.006$ & $0.535 \pm 0.071$ & small & metacentric \\
\hline 7 & 0.17 & 0.32 & 0.49 & $0.026 \pm 0.007$ & $0.653 \pm 0.134$ & small & submetacentric \\
\hline 8 & 0.21 & 0.24 & 0.45 & $0.024 \pm 0.008$ & $0.533 \pm 0.143$ & small & metacentric \\
\hline 9 & 0.17 & 0.19 & 0.36 & $0.019 \pm 0.009$ & $0.527 \pm 0.071$ & small & metacentric \\
\hline 10 & 0.11 & 0.17 & 0.28 & $0.015 \pm 0.011$ & $0.607 \pm 0.049$ & small & submetacentric \\
\hline Sex-chromo. & 0.79 & 0.96 & 1.75 & $0.093 \pm 0.014$ & $0.548 \pm 0.111$ & large & metacentric \\
\hline
\end{tabular}

Table 4. Mean of length short arm chromosome (Ls), length long arm chromosome (LL), length total arm chromosome (LT), relative length (RL), centromeric index (CI) and standard deviation (SD) of $\mathrm{RL}, \mathrm{CI}$ from metaphase chromosomes of 20 cells in male and female river giant toad (Bufo asper) $2 n$ (diploid) $=22$

\begin{tabular}{|c|c|c|c|c|c|c|c|}
\hline $\begin{array}{c}\text { Chromosome } \\
\text { pairs }\end{array}$ & Ls & $\mathrm{LL}$ & LT & $\mathrm{RL}+\mathrm{SD}$ & $\mathrm{CI}+\mathrm{SD}$ & $\begin{array}{c}\text { Chromosome } \\
\text { size }\end{array}$ & $\begin{array}{c}\text { Chromosome } \\
\text { type }\end{array}$ \\
\hline 1 & 0.73 & 0.95 & 1.68 & $0.087 \pm 0.012$ & $0.565 \pm 0.091$ & large & metacentric \\
\hline 2 & 0.60 & 0.87 & 1.47 & $0.076 \pm 0.008$ & $0.591 \pm 0.072$ & large & metacentric \\
\hline 3 & 0.49 & 0.85 & 1.34 & $0.069 \pm 0.006$ & $0.634 \pm 0.014$ & large & submetacentric \\
\hline 4 & 0.56 & 0.56 & 1.12 & $0.058 \pm 0.002$ & $0.500 \pm 0.184$ & large & metacentric \\
\hline 5 & 0.37 & 0.50 & 0.87 & $0.045 \pm 0.001$ & $0.574 \pm 0.139$ & medium & metacentric \\
\hline 6 & 0.23 & 0.33 & 0.56 & $0.029 \pm 0.006$ & $0.589 \pm 0.043$ & small & metacentric \\
\hline 7 & 0.16 & 0.35 & 0.51 & $0.026 \pm 0.007$ & $0.686 \pm 0.009$ & small & submetacentric \\
\hline 8 & 0.23 & 0.23 & 0.46 & $0.024 \pm 0.008$ & $0.500 \pm 0.142$ & small & metacentric \\
\hline 9 & 0.18 & 0.23 & 0.41 & $0.021 \pm 0.009$ & $0.560 \pm 0.101$ & small & metacentric \\
\hline 10 & 0.11 & 0.20 & 0.31 & $0.016 \pm 0.011$ & $0.645 \pm 0.088$ & small & submetacentric \\
\hline Sex-chromo. & 0.85 & 1.07 & 1.92 & $0.099 \pm 0.015$ & $0.557 \pm 0.100$ & large & metacentric \\
\hline
\end{tabular}


rochromatin region of short arm and $\mathrm{W}$ chromosome but not show on $\mathrm{Z}$ chromosome. Moreover, he showed that a dark band by C-banding will become a constriction when stained by NOR-banding technique.

Our results indicated that $B$. melanostictus's chromosome is being in the evolutionary change. Moreover, its $\mathrm{X}$ and $\mathrm{Y}$ chromosome have the same type and also equal size but have different band patterns by banding techniques. For B. macrotis, B. parvus and B. asper, we can not study them by G-banding and C-banding techniques because of the few amount of samples and unsuccessful operation. However, we have an agreement that the sex-determination of B. macrotis, B. parvus and B. asper should be XY system.

\section{References}

Beckert, W. H. and Doyle, W. 1967. Anuran karyotype methodology I: The karyotype of Bufo marinus. Can. S. Genet. Cytol. 9: 297-301.

Bogart, J. P. 1966. Chromosome number difference in the genus Bufo: The Bufo regularis species group. Evolution 22: $42-45$.

Boulenger, G. A. 1887. On new batrachians from Malacca. Ann. Mag. Nat. Hist. ser. 19, 5: 345-348

Campiranon, A. 2003. Cytogenetics. Department of Genetics, Faculty of Science, Kasetsart University, Bangkok, Thailand.

Chaiyasut, K. 1989. Cytogenetics and cytotaxonomy of the family Zephyranthes. Department of Botany, Facultly of science, Chulalongkorn University, Bangkok, Thailand.

Cole, C. J., Lowe, C. H. and Wright, J. W. 1968. Karyotype of eight species of toads (genus Bufo) in North America. Copeia 1: $96-100$.

Duellman, W. E. 1982. Synopsis and classification of living organism. Mc-Graw Hill book: New York, USA.

Green, D. M. 1998. Cytogenetics of the endemic New Zeland frog, Leiopelma hocostetteri: Extraordinary supernumerary chromosome variation and a unique sex-chromosome system. Chromosoma 97: 55-70.

Gravenhorst, J. L. C. 1829. Ichneumonologia Europaea·Pars III.

Iturra, P. and Veloso, A. 1989. Further evidence for early sex chromosome differentiation of Anuran species. Genetica 78: 25-31.

Kuramoto, M. 1980. Karyotypes of several frogs from Korea, Taiwan and the Philipines. Experientia 36: 826-828.

Mahony, M. J. 1991. Heteromorphic sex chromosomes in the Australian frog, Crinia bilingual (Anura: Myobatrachidae). Genome 34: 334-337.

Melo, A. S., Recco-Pimentel, S. M. and Giaretta, A. A. 1995. The karyotype of the stream dwelling frog, Megaelosia massari (Anura, Leptodactilidae, Hylodinae). Cytologia 60: 49-52.

Narkkasem, N. 1975. The study on growth rate and karyotype of lowland frog (Rana rugulosa), bubble frog (Kaloula pulchra) and common Indian toad (Bufo melanostictus). M.Sc. thesis, Chulalongkorn University, Bangkok, Thailand.

Nishioka, M., Hanada, H., Miura, I. and Ryuzaki, M. 1994. Four kinds of sex chromosomes in Rana rugosa. Sci. Rep. Lab. Amphibian Bilo., Hiroshima University 13: 1-34.

-, Okumoto, H., Ueda, H. and Ryuzaki, M. 1987. Karyotypes of brown frogs distribution in Japan, Korea, Europe and North America. Sci. Rep. Lab. Amphibian Biol., Hiroshima University 9: 165-212.

Ota, H. and Matsui, M. 1995. Karyotype of rain frog, Platymantis pelewensis, from Belau Macronesia with comments on its systematic implications. Pac. Sci. 49: 296-300.

Rooney, D. E. 2001. Human cytogenetics: Constitutional analysis. Oxford University Press: Oxford, UK.

Schempp, W. and Schmid, M. 1981. Chromosome banding in amphibian VI. BrdU-replication patterns in Anura and demonstration of XX/XY ZZ sex chromosomes in Rana esculenta. Chromosoma 83: 697-710.

Schmid, M. 1978a. Chromosome banding in amphibia I. Constitutive heterochromatin and nucleolus organizer regions in Bufo and Hyla. Chromosoma 66: 361-388.

- 1978b. Chromosome banding in amphibian II. Constitutive heterochromatin and nucleolus organizer regions in Ranidae, Microhylidae and Rhacophoridae. Chromosoma 68: 131-148.

- 1980. Chromosome banding in amphibia V. Highly differentiated ZW/ZZ sex chromosomes and exceptional genome size in Pyxicephalus adspersus (Anura, Ranidae). Chromosoma 80: 69-96.

-, Haaf, T., Beatrix, G. and Sims, S. 1983. Chromosome banding in amphibia VIII. An unusual XY/XX sex chromosome system in Gastrotheca riobambae (Anura, Hylidae). Chromosoma 88: 69-82.

—, Enderle, E., Schindler, O., and Schempp, W. 1989. Chromosomal banding and DNA replication patterns in bird karyotypes. Cytogenet. Cell Genet. 52: 139-146.

- , - Geile, B. and Sims, B. 1990. Chromosome banding in amphibia XV. Two types of Y chromosomes and heterochromatin hypervariability in Gastrotheca pseustes (Anura, Hylidae). Chromosoma 99: 413-423. 
—, Nanda, I., Epplen, J. T., Steilein, C., Kausch, K. and Haaf, T. 1991. Sex-determining mechanisms and sex chromosomes in amphibian. In Green, D. M. and Sessions, S. K. Amphibian cytogenetics and evolution. pp. 393-430, California: Academic Press, USA.

—, Ohta, S., Steinlein, C. and Guttenbanch, M. 1993. Chromosome banding in amphibia XIX. Primitive ZW/ZZ sex chromosomes in Bergeria buergeri (Anura, Rhacophoridae) Cytogenet. Cell Genet. 62: 238-246.

—, Steinlein, C., Feichtinger, W., de Almeida, C. G. and Duellman, W. E. 1988. Chromosome banding in amphibia XIII. Sex chromosomes, heterochromatin and meiosis marsupial frogs (Anura, Hylidae). Chromosoma 97: 33-42.

- - - and - 1992. Chromosome banding in amphibia XVII. First demonstration of multiple sex chromosome in amphibians: Eleutherodactylus maussi (Anura, Leptodactilidae). Chromosoma 101: 284-292.

Schneider, J. C. 1799. Historiae Amphibiorum naturalis et liferariae. Iena.

Solari, A. J. 1994. Sex chromosome and sex determination in vertebrates. CRC Press, USA.

Summer, A. T. 1990. Chromosome Banding. Unwin Hyman, Boston.

Supaporm, T. and Kanlayaprasith, P. 1990. Chromosome study of bubble frog (Kaloula pulchra) and common Indian toad (Bufo melanostictus). The abstract of 7th genetically academic seminar. 107-109 p.

Taylor, E. H. 1962. The Amphibian fauna of Thailand. The University of Kansas Science Bulletin 43: 265-599. 